North, Michael, Kultureller Austausch. Bilanz und

Perspektiven der Frühneuzeitforschung

\title{
Marie Drut-Hours
}

\section{OpenEdition}

\section{Journals}

Édition électronique

URL : http://journals.openedition.org/ifha/6660

DOI : 10.4000/ifha.6660

ISSN : 2198-8943

Éditeur

IFRA - Institut franco-allemand (sciences historiques et sociales)

Référence électronique

Marie Drut-Hours, « North, Michael, Kultureller Austausch. Bilanz und Perspektiven der

Frühneuzeitforschung », Revue de l'IFHA [En ligne], Date de recension, mis en ligne le 01 janvier 2011,

consulté le 10 décembre 2020. URL : http://journals.openedition.org/ifha/6660 ; DOI : https://doi.org/ $10.4000 /$ ifha. 6660

Ce document a été généré automatiquement le 10 décembre 2020.

(C)IFHA 


\title{
North, Michael, Kultureller
} Austausch. Bilanz und Perspektiven der
Frühneuzeitforschung

\author{
Marie Drut-Hours
}

1 Ce volume rassemble vingt contributions présentées au colloque de l'Association des historiens allemands tenu à Greifswald en 2007. Elles sont groupées en six thématiques faisant chacune l'objet d'une brève présentation liminaire.

2 La première partie développe la réflexion théorique sur les notions de transferts et échanges culturels. M. Werner milite pour une « histoire croisée » prenant en compte les interactions multilatérales entre les acteurs des transferts, ainsi que les mutations qu'ils subissent eux-mêmes au cours de ces processus. M. Steer montre, à partir du cas des communautés juives européennes (et notamment de Salonique), comment le concept de transfert culturel conduit à une vision différenciée des communautés et de leur intégration dans leur environnement. C. Zwierlein voit dans la notion de transferts culturels un outil d'analyse permettant de rétablir un lien entre des approches historiques spatiales et temporelles, souvent dissociées dans l'historiographie de l'époque moderne des dernières décennies. P. Burke attire enfin l'attention sur la terminologie utilisée et dénonce l'inadéquation du concept de " transfert ", lui préférant celui « d'échanges » qui rend mieux compte de la réciprocité du processus.

3 Trois études de cas illustrent la vitalité des échanges intra-allemands dont G. Schmidt rappelle combien ils ont été favorisés par la diversité et la pluralité fondatrices de la nation germanique. Prenant à rebours l'historiographie traditionnelle des communautés huguenotes, M. Asche montre que les migrations n'ont pas seulement favorisé les échanges culturels, mais aussi conduit à la formation de microsociétés parallèles. T. Töpfer constate que les connections entre collèges et universités, créatrices de modèles éducatifs et culturels, ont déterminé au sein du Reich des espaces culturels indépendants des frontières politiques, entre lesquels se sont développés des échanges multiples. Partant d'un fait judiciaire précis, N. Grochowina montre comment la concurrence entre divers systèmes juridiques au sein de l'Empire a rendu nécessaire, 
dans la pratique, l'intervention de juristes appelés, comme arbitres, à favoriser les transferts de valeurs d'un système à l'autre.

4 La troisième partie aborde la question des relais du pouvoir central dans un espace politique donné en termes de transferts et d'échanges : K. Gottschalk analyse l'émergence d'une nouvelle culture administrative en Hesse-Cassel au fil des réformes du XVIIIe siècle et de leur assimilation par les responsables locaux. Les cas de la Livonie polonaise au XVIIe siècle (B. Dybás) et du comitat de Szatmar en Hongrie orientale à la fin du XVIIIe siècle (A. Vári) illustrent, au contraire, les résistances aux réformes imposées du haut et les aléas de l'interaction entre différents niveaux de pouvoirs.

Trois études tentent de reconstituer les processus de construction et de diffusion des savoirs professionnels dans des domaines différents. Analysant des traités d'architecture allemands de la fin du XVe et du XVIe siècles, S. Paulus conteste une définition trop simpliste de l'architecture de la Renaissance à l'aune du degré d'imitation formelle des modèles italiens en montrant comment la convergence avec les traités italiens sur les principes fondamentaux rationnels pouvait fort bien s'accommoder de la fidélité aux traditions stylistiques nationales. H.V. Lammel suit les adaptations et mutations d'un traité d'anatomie italien du XIVe siècle dans l'édition qui en est faite à Rostock au début du XVIe siècle pour un lectorat de lettrés humanistes. M. Häberlein évoque la formation des fils de marchands de l'Allemagne du Sud aux XVIe et XVIIe siècles, fondée sur les échanges pratiques.

6 La cinquième partie est centrée sur les acteurs des transferts avec trois contributions qui mettent en évidence le rôle majeur des marchands. M. Klebusek montre comment ils utilisent leurs réseaux pour développer le commerce des livres et des œuvres d'art, pour leur propre compte ou pour celui de commanditaires. K. Nyberg présente le cas de la Skeppsbron nobility, groupe de marchands suédois et étrangers installés à Stockholm qui ouvrirent le marché suédois aux importations et stimulèrent autant la naissance d'une industrie nationale que l'émergence de nouveaux comportements socioculturels, devenus la marque identitaire de cette élite multiculturelle. K. Siebenhüner met en évidence l'étendue des connections internationales des négociants en joaillerie.

7 La dernière thématique porte sur les processus d'acculturation réciproque dans les échanges entre pays européens et extra-européens nés des mouvements de colonisation. M. Meadow et H. Pietschmann illustrent, par l'analyse de diverses peintures, les effets précoces de la symbiose entre cultures amérindienne et judéochrétienne. M. Neuwirth montre comment l'expansion portugaise a suscité, de l'Afrique à l'Asie, dès le XVIe siècle, l'essor d'artisanats indigènes mêlant traditions locales et européennes pour satisfaire les clientèles des deux origines. M. Krieger étudie l'inversion des processus d'acculturation visible dans l'habitat des élites sur la côte de Coromandel à partir de l'expansion britannique en Inde au milieu du XVIIIe siècle.

8 L'ensemble des contributions se veut une invitation à développer les recherches pour réduire le champ de l'ignorance qui a longtemps fait prévaloir une vision simpliste des transferts, conçus comme un processus unilatéral et déséquilibré entre cultures dominantes et cultures dominées.

9 Marie Drut-Hours (université Paul-Verlaine, Metz) 